\title{
MECANISMOS DE INTERIORIZAÇÃO DOS CUSTOS AMBIENTAIS NA INDÚSTRIA: RUMO A MUDANÇAS DE COMPORIAMENTO
}

\author{
Carmem Silvia Sanches \\ Mestre e doutoranda em Administração de \\ Empresas pela EAESP/FGV. \\ E-mail: 6941011 @eaesp.fgvsp.br
}

RESUMO: A fim de motivar mudanças no comportamento da indústria em relação ao meio ambiente, estão sendo implementados, especialmente nos países desenvolvidos, mecanismos de interiorização de custos ambientais. Dentre os mecanismos até então disponíveis, podem-se destacar, mais especificamente, as abordagens de comando e controle, os instrumentos econômicos e a auto-regulação, que são aqui apresentados e amparados por prós e contras, assim como as vantagens e desvantagens sob o ponto de vista do empresariado, pois há uma intensa polêmica em torno da eficiência e eficácia de cada um deles para produzir as respostas desejadas por parte das empresas industriais.

ABSTRACT: In order to motivate changes in the behaviour of the industry regarding environment, interiorization mechanisms of environment costs have been developed, specially in developed countries. Among the available mechanisms, we can emphasize more specifically the approaches of command and control, the economic instruments, and the auto-regulation. There is an intensive controversy related to efficiency and effectiveness of each mechanism to produce the desirable answers from industrial enterprises, and they are here presented and supported by pros and cons, as well as advantages and disadvantages under the point of view of management.

PALAVRAS-CHAVE: meio ambiente, indústria, mecanismos de interiorização de custos ambientais, autoregulação, ISO 14000.

KEY WORDS: environment, industry, interiorization mechanisms of environment costs, auto-regulation, ISO 14000. 
As atividades industriais são de extrema relevância para a conformação da sociedade moderna, influenciando (e sendo influenciadas por) valores e atitudes dessa sociedade, assim como seu processo de desenvolvimento e crescimento econômico. Até algumas décadas atrás, porém, esse processo não considerava os efeitos adversos nos ecossistemas e na própria sociedade, permitindo que emergissem problemas sociais e ambientais que cada vez mais tornamse críticos para o bem-estar da sociedade, como a miséria e a pobreza, o desemprego, a devastação de solos produtivos, a poluição das águas e do ar, entre outros.

A Conferência das Nações Unidas sobre o Meio Ambiente Humano (realizada em Estocolmo, em 1972) evidenciou que os problemas ambientais têm um caráter relevante para a sociedade moderna e envolvem a participação de todos os agentes econômicos. A Conferência das Nações Unidas sobre Meio Ambiente e Desenvolvimento e o Fórum Global das Organizações Não-Governamentais (ONGs), realizados em 1992 no Rio de Janeiro, ratificaram essa importância e a necessidade de cooperação.

De uma forma geral, pode-se dizer que toda a trajetória da questão ambiental, desde a década de 70 até o momento, enfatiza que as soluções envolvem ações e responsabilidades de todos os agentes sociais e econômicos, tais como a sociedade civil, os governos e também o setor privado, evidenciando-se ainda que são necessárias mudanças nas práticas econômicas em todo mundo, a fim de se estabelecer um novo patamar de decisões e critérios que orientem o uso de todos os recursos - financeiros, tecnológicos, físicos, humanos e naturais.

$\mathrm{Na}$ indústria, a conscientização acerca da problemática e da necessidade de mudanças já se vem ampliando, e o desafio lançado em fóruns internacionais está sendo colocado às empresas dentro de seus próprios ambientes de negócios, mediante pressões cada vez maiores exercidas por diversos agentes, particularmente a sociedade civil e os governos.

$A$ atuação da sociedade civil e dos governos sobre a indústria, a fim de que esta incorpore a problemática ambiental em suas atividades produtivas e de negócios, vem-se intensificando através de diversas formas, dentre elas as pressões exercidas por comunidades locais e grupos ambientalistas diretamente sobre as empresas, as regulamentações e outras políticas ambientais governamentais etc. Nesse contexto de pressões em prol da causa ambiental, vale destacar particularmente a ampliação do papel e da atuação das organizações não-governamentais (ONGs), entidades privadas sem fins lucrativos. $O$ principal papel das ONGs tem sido o de atuar como grupos de pressão junto aos poderes econômicos e políticos - ou mesmo como gestoras de programas de conservação de reservas naturais, de pesquisa científica e de educação ambiental junto às comunidades - proporcionando uma ampliação da percepção pública acerca dos problemas ambientais, assim como a mobilização de parte da sociedade em busca de soluções para os problemas sociais e ambientais.

Mas mesmo com todas essas pressões, há numerosos obstáculos à mudança imediata nas práticas industriais, como será mostrado a seguir.

\section{As dificuldades de lidar com
as questóes ambientais por
parte da indústria reflete as
dúvidas, as incertezas e os
valores a que a sociedade
como um todo está sujeita.}

\section{AGENTES DE MUDANÇAS}

A problemática ambiental exige conscientização para que se adotem soluções práticas, viáveis. As soluções mais eficazes, conforme atestam inclusive documentos internacionais (como o relatório The Limits to Growth, do Clube de Roma, de 1974, ${ }^{1}$ o relatório Nosso Futuro Comum, da Comissão Mundial de Meio Ambiente e Desenvolvimento (CMMAD), ${ }^{2}$ e a Agenda $21^{3}$ ), relacionamse à mudança do comportamento dos agentes econômicos. No entanto, algumas dificuldades para a realização dessas mudanças dizem respeito ao comportamento dos próprios agentes indutores sobre a indústria, a saber:

a) a sociedade civil: há uma aparente relutância por parte dos consumidores em reduzir significativamente seus próprios níveis de consumo. Um exemplo refere-se à dependência que a sociedade tem do carro para sua mobilidade e ao fato de ainda não
1. VIGEVANI, Tulio. Meio Ambiente $e$ relações internacionais: a questão dos financiamentos. São Paulo, IEA/USP (Coleção Documentos, Série Assuntos Internacionais, 31), 1994, p. 11-13.

2. COMISSÃO MUNDIAL SOBRE MEIO AMBIENTE E DESENVOLVIMENTO (CMMAD). Nosso Futuro Comum. 2 ed., Rio de Janeiro: Editora da Fundação Getúlio Vargas, 1994.

3. UNCED. Agenda 21. Rio de Janeiro: United Nations Conference on Environment and Development (UNCED), 1992. 
ter exercido uma mudança de comportamento radical em relação a esse produto. Já em países em desenvolvimento, como o Brasil, grande parcela da população vive, de forma tão aguda, problemas econômicos e sociais relacionados à subsistência e às necessidades básicas, que tendem a excluir a problemática ambiental de suas preocupações.

b) o Governo: muitas das medidas e políticas adotadas visam a "alcançar" a natureza no sentido de tentar reparar os danos acumulados no passado. Assim, concentram-se muito mais em tratar os efeitos ambientais visíveis, como a poluição, sem se preocupar com as verdadeiras causas e preveni-las.

A essas dificuldades, referentes aos principais grupos de pressão sobre a indústria, adicionam-se outras barreiras que vêm dificultando não só a adoção de práticas ambientais, mas mudanças de comportamento de uma forma geral. Dentre essas barreiras, destacam-se: ${ }^{4}$

a) falha dos mercados em refletir os custos sociais e ambientais, incluindo o custo para as gerações futuras, de bens ou serviços;

b) a dificuldade de estabelecerem-se, com certeza, riscos, custos e benefícios;

c) a falta de boa vontade generalizada de indivíduos e organizações em fazer investimentos de longo prazo, com prazos de retorno incertos;

d) o desejo e a necessidade generalizados (se inatos ou socialmente instigados) de preservar ou maximizar interesses pessoais individuais e corporativos;

4. BUCHHOLZ, Rogene A.; MARCUS, Alfred A. POST James E. Managing Environmental issues: a Casebook. Englewood Cliffs, N.J.: Prentice-Hall, 1992, p. xi-xii.

5. FISHER, S.; DORNBUSH, R Introduction to Microeconomics. New York, McGraw Hill, 1983. Citado por COMUNE, Antonio E Meio Ambiente, Economia e Economistas: uma breve discussão, p. 50. In MAY, P. H.; MOTTA, R. S. (Orgs.). Valorando a Natureza Análise Econômica Para o Desenvolvimento Sustentável. Rio de Janeiro: Campus, 1994, p. 45-59.

6. COMUNE, Antonio E. Meio Ambiente, Economia e Economistas: uma breve discussão. In MAY, P. H.; MOTTA, R. S. (Orgs.). Valorando a Natureza - Análise Económica Para o Desenvolvimento Sustentável. Rio de Janeiro: Campus, 1994, p. $45-59$ jeita. Entretanto, esperar que a sociedade e/ ou os governos encontrem as melhores soluções para então adotar as práticas mais adequadas pode levar empresas industriais a perderem a oportunidade de obter vantagens competitivas num mercado que já se mostra bastante concorrido, marcado por incertezas, instabilidade e rápidas mudanças.

O mercado tem um importante papel a desempenhar na motivação da mudança de comportamento e da adoção de medidas que protejam o meio ambiente, e muitas das soluções só serão encontradas por esse mecanismo. Porém, constata-se que os problemas ambientais crescem em grande parte porque os preços pagos pelos consumidores por bens e serviços não refletem totalmente os custos que sua provisão, uso e descarte impõem sobre o meio ambiente. Na prática, o mercado freqüentemente falha, e também os governos.

$O$ Governo tem interferido no mercado para compensar as falhas e proteger o meio ambiente. Tal ação baseia-se no conceito de "economias externas ou externalidades", desenvolvido no campo das ciências econômicas para tratar com as questões dos custos sociais. Segundo Fisher \& Dornbush:" "uma externalidade surge sempre que a produção ou o consumo de um bem tem efeitos paralelos sobre os consumidores ou produtores envolvidos, efeitos estes que não são plenamente refletidos nos preços de mercado".

Para que as externalidades sejam neutralizadas, podem-se aplicar medidas que internalizem os custos ambientais. A internalização ou interiorização dos custos ambientais é uma maneira de equilíbrio das forças de mercado e de distribuição mais justa, em termos monetários, dos danos que a sociedade está suportando como efeitos da modificação da qualidade do meio ambiental. Não se trata, porém, como nota Comune, 6 " de operação simples e fácil, pois os instrumentos econômicos disponiveis para tanto não são perfeitamente satisfatórios". Com isso, tem-se tornado parte de um debate amplo sobre qual a forma mais eficiente de internalizar os custos ambientais na indústria e refleti-los nos preços dos produtos. Em âmbito internacional, já há um acordo entre os países membros da Organização para a Cooperação e Desenvolvimento Econômico (OCDE), firmado em 1972, concordando em basear suas políticas ambientais em um "Princípio do Poluidor Pagador" (PPP). Seu mecanismo in- 
corre na interferência nas decisões do consumidor, mediante a elevação do preço dos produtos ambientalmente mais nocivos. $\mathrm{O}$ aumento dos preços desses produtos envia um sinal de mercado ao consumidor, para que esse procure um substituto mais limpo. Como os consumidores reagem, os produtores devem fazer o mesmo.

\section{MECANISMOS DE MUDANÇAS}

Sob o Princípio do Poluidor Pagador, há em vigor três mecanismos de internalização dos custos ambientais nas atividades da indústria, apontados por Schimidheiny, ${ }^{7}$ a saber:

1. Comando e controle: trata-se basicamente de regulamentações governamentais, que incluem padrões de desempenho para as tecnologias e os produtos, padrões de emissão e de efluentes etc.

2. Instrumentos econômicos: trata-se de esforços para alterar os preços dos recursos e dos bens e serviços no mercado, através de alguma forma de ação governamental que afetará o custo da produção e/ou do consumo.

3. Auto-regulação: trata-se de iniciativas tomadas pelas empresas ou por setores da indústria a fim de se auto-regularem mediante a adoção de padrões, monitoramentos, metas de redução da poluição, e assim por diante.

Os dois primeiros mecanismos fazem parte de políticas ambientais implementadas pelos governos. A política ambiental governamental pode também usar outras ferramentas de incentivo às práticas ambientais, como, por exemplo, a educação ambiental, o desenvolvimento de capacidade tecnológica etc., mas que não são formas utilizadas especificamente para internalizar os custos ambientais na indústria e refletilos nos preços dos produtos, embora não sejam incompatíveis com eles.

\section{Instrumento de Comando e Controle}

O "comando e controle" é um instrumento de política ambiental utilizado pelo governo para combater os efeitos da degradação do meio ambiente mediante o uso do poder de polícia do Estado. Os principais mecanismos da "abordagem de comando e controle" são: normas e padrões, licenças e permissões e controle do uso do solo e da água. Dentre es- ses, as normas e padrões têm sido mais utilizados na regulamentação ambiental em países desenvolvidos e em desenvolvimento.

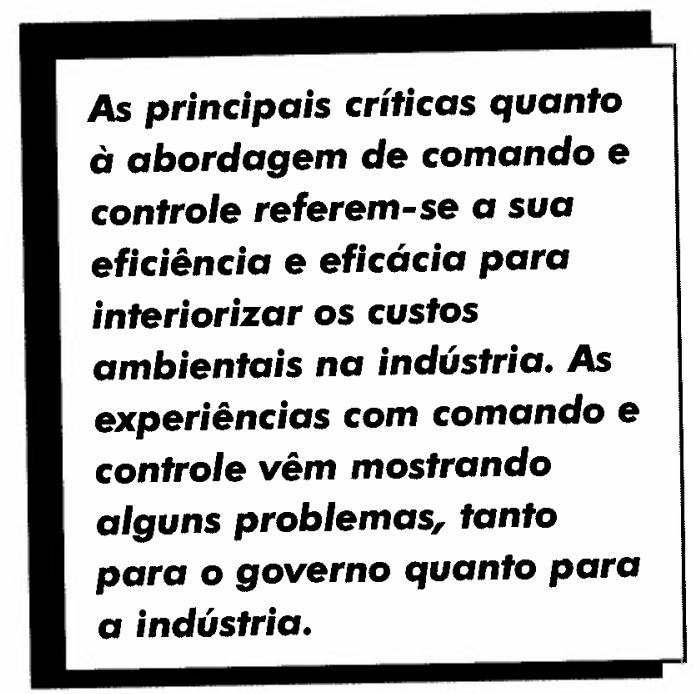

As normas e padrões definem os objetivos ambientais e estabelecem as quantidades de concentração de substâncias que podem ser lançadas no ar, na água e no solo ou que, eventualmente, possam estar contidas em um bem ou serviço. Em geral, é possível identificar três tipos de normas e padrões:

a) normas e padrões de qualidade ambiental: dizem respeito à qualidade média do meio receptor da poluição e estabelecem a quantidade máxima aceitável neste ambiente;

b) normas e padrões de emissão: incidem diretamente nas emissões das atividades que poluem, informando a quantidade máxima de concentração de poluentes lançada por uma fonte específica. Essas normas ou padrões podem ser categorizadas em tecnológicos e de performance. Nos primeiros, a tecnologia é estipulada, para que as firmas cumpram as determinações ambientais. Nos segundos, adotam-se medidas de desempenho (volume ou concentração de poluentes que podem ser emitidos), existindo flexibilidade para que os poluidores escolham as alternativas que considerem mais eficientes;

c) normas e padrões de produtos: procuram regulamentar a poluição gerada pelas características dos produtos finais e estabelecem requisitos mínimos com relação às substâncias contidas em um produto e à tecnologia empregada em sua elaboração.
7. SCHMIDHEINY, Stephan. Mudando o rumo: uma perspectiva empresarial global sobre o desenvolvimento e meio ambiente. Rio de Janeiro: Editora da Fundação Getúlio Vargas, 1992, p. 19. 
8. COMUNE, Antonio E. Op. cit.

9. GUIMARÃES, Paulo C. V.; DEMAJOROVIC, Jacques; OLIVEIRA Roberto G. Estratégias Empresariais e Instrumentos Econômicos de Gestão. São Paulo, Anais do III Encontro Nacional de Gestão Empresarial e Meio Ambiente, v. I, p. 17-29, 1995.

10. GUIMARÃES, Paulo C. V. DEMAJOROVIC, Jacques; OLIVEIRA, Roberto G. Op. cit.

11. GUIMARÄES, Paulo C. V. DEMAJOROVIC, Jacques; OLIVEIRA Roberto G. Op. cit.

12. SCHMIDHEINY, Stephan. Op. cit., $p$ 24; GUIMARÃES, Paulo C. V Instrumentos Econômicos para Gerenciamento Ambiental: a cobranca pelo uso da água no Estado de São Paulo. Revista de Administração de Empresas v. 33, n. 5 , p. 88-97, Set/0ut 1993 SHRIVASTAVA, Paul. Greening Business: Profiting the Corporation and the Environment. Cincinnati, Ohio: Thompson Executive Press, 1996, p. 149 158.

13. GUIMARÃES, Paulo C. V.; DEMAJOROVIC, Jacques; OLIVEIRA Roberto G. Op. cit.

14. BARDE, Jean-Philippe. The Economic Approach to the Environment. The OECD Observer, n. 158, p. 12-15, Jun/Jul 1989.

15. BARDE, Jean-Philippe; OPSCHOOR Johanes B. From Stick to Carrot in the Environment. The OECD Observer, $n$ 186, p. 23-27, Feb/Mar 1994 GUIMARÄES, Paulo C. V.; DEMAJOROVIC Jacques; OLIVEIRA, Roberto G. Op. cit.
Na verdade, se não houver monitoramento, as normas e padrões de meio ambiente não pressupõem em si mesmas nenhum mecanismo econômico. Conforme notam Comune $^{8}$ e Guimarães et al., ${ }^{9}$ esse sistema tem relação com o princípio de internalização do efeito externo porque, em geral, uma multa é aplicada caso ocorram infrações. Além disso, o atendimento às normas legislativas exige modificações operacionais, o que eleva os custos das operações, identificandoos à internalização de custos ambientais. $\mathrm{Na}$ falta de poder de execução - ou enforcement - o único incentivo para o cumprimento das normas é a consciência social ou a exigência do próprio mercado.

Quanto às licenças e permissões, normalmente estão ligadas à política de controle da qualidade do ar, da água e do solo. As condições específicas para obtê-las variam de país para país, mas em geral mantêm-se algumas considerações básicas. Essas condições são: obediência a formas específicas de procedimento; escolha de local que minimize os impactos ambientais e econômicos; instalação de planta de tratamento ou equipamentos de controle de poluição em um prazo de tempo determinado; e adoção de outras medidas de proteção ambiental. Uma vantagem das licenças e permissões está relacionada à possibilidade de serem retiradas ou suspensas sempre que haja um outro interesse com maior prioridade. Essa opção implica o pagamento de uma taxa que pode até mesmo ser usada como cobertura dos custos dos programas de controle de poluição. ${ }^{10}$

Por sua vez, o controle do uso da água e do solo é aplicado normalmente em nível local, como instrumento de preservação ambiental. Pode impedir que indústrias poluidoras localizem-se em áreas não apropriadas ou pode controlar a densidade populacional. Seu problema está relacionado à sua vulnerabilidade às pressões políticas e econômicas, que podem levar a um desrespeito dos objetivos ambientais. ${ }^{11}$

A abordagem "comando e controle" parece ser, para muitos, mais conveniente, pois tanto a indústria quanto o governo são mais experientes em matéria de regulamentação do que em outros mecanismos. Em geral, os governos acham que a regulamentação é mais segura para atingir os objetivos ambientais e a indústria julga poder influenciá-la por meio da negociação. ${ }^{12}$

As principais críticas quanto à abordagem de comando e controle referem-se a sua eficiência e eficácia para interiorizar os custos ambientais na indústria. As experiências com comando e controle vêm mostrando alguns problemas, tanto para o governo quanto para a indústria. Guimarães et al ${ }^{13}$ destacam que os recursos necessários (financeiros, pessoal, organizacionais etc.) e o tempo empregado pelas agências governamentais na abordagem de comando e controle são altos. Do lado da indústria, a abordagem exige normalmente a padronização da tecnologia, e isso não gera incentivos para a busca de soluções alternativas, que poderiam ser menos poluentes ou mais custo-efetivas.

O "comando e controle" exerce importante influência no sentido de internalizar os custos ambientais e induzir a indústria a adotar práticas ambientais em conformidade com os objetivos estabelecidos. No entanto, essa abordagem exige informações e custos administrativos elevados, que acabam por se tornar um elemento oneroso tanto para o governo quanto para a própria sociedade. Além do alto custo social dessa ferramenta, ela não incentiva as empresas a irem além dos padrões estabelecidos e tentarem resolver os problemas ambientais mais eficientemente, e a custos mais baixos. Trata-se, enfim, de um instrumento que incentiva a indústria a adotar práticas reativas, reagindo às regulamentações, $\mathrm{e}$ não buscando tecnologias alternativas ou práticas mais convenientes.

\section{Instrumentos econômicos}

Os instrumentos econômicos são uma outra abordagem de política ambiental governamental, diretamente derivados da teoria econômica das externalidades. Seu mecanismo busca embutir nos preços dos produtos os custos da poluição e dos danos ambientais, induzindo mudanças de comportamento nos consumidores. Segundo Barde, ${ }^{14}$ os instrumentos econômicos operam como incentivos financeiros aos poluidores, que selecionam as soluções mais vantajosas: poluir e pagar, ou investir no controle da poluição para evitar pagar.

Já foram identificados mais de 100 tipos de instrumentos econômicos em uso nos países-membros da OCDE, que podem ser englobados em quatros modalidades principais: licenças negociáveis; cobranças e taxas sobre emissões; cobranças sobre produtos; sistemas depósito-restituição. ${ }^{15}$ 
As licenças negociáveis são cotas, permissões ou tetos de poluição, ou, de forma mais geral, direitos para usar o meio ambiente. São comercializados pelas autoridades competentes, que podem alocá-los gratuitamente ou oferecê-los para venda. Nesse caso, as licenças podem ser negociadas, vendidas e compradas, sem interferência central, mas dentro dos limites das regras estabelecidas pelas autoridades.

A abordagem das licenças negociáveis foi largamente utilizada nos Estados Unidos, principalmente para controlar a poluição do ar. Segundo Grubb, ${ }^{16}$ dado seu êxito inicial, o governo norte-americano as transformou no principal elemento da legislação Clean Air $A c t$, que regula as emissões de dióxido de enxofre. Até agora, as licenças negociáveis foram utilizadas em apenas 4 países (Alemanha, Austrália, Canadá e Estados Unidos), e o sistema apresentou um baixo custo de implementação. Ainda não há certeza, porém, de que seja possível utilizá-las no plano global, especialmente em países que não disponham de uma estrutura bem desenvolvida para esse tipo de transação.

Já as cobranças e taxas sobre emissões estabelecem uma taxa a ser cobrada sobre unidades incrementais de poluição. São aplicadas às emissões de poluentes do ar, da água e do solo, e também sobre poluição sonora. São apropriadas quando a alteração ambiental pode ser estimada corretamente e menos adequadas quando se pretende garantir um grau de qualidade ambiental geral e não só quanto a poluentes individuais. Alguns exemplos são as cobranças e taxas sobre óxidos sulfúricos na França e a cobrança sobre óxidos nítricos na Suécia.

Quanto às cobranças sobre produtos, são taxas que incidem sobre o preço do produto que cause algum tipo de poluição na fase de produção, consumo ou descarte. São projetadas para alterar os preços relativos de produtos poluentes, como combustíveis, fertilizantes, pesticidas, baterias, materiais de embalagem etc. $\mathrm{O}$ objetivo é estimular alternativas mais eficientes no combate à poluição.

Os sistemas depósito-restituição, por sua vez, consistem no estabelecimento de uma caução, associada à compra de um produto cuja restituição é vinculada à devolução da embalagem ou do próprio produto após o seu uso. Seu objetivo é o de estimular a reciclagem e a prevenção da poluição, podendo ser da ini- ciativa do governo e/ou das próprias empresas. Nos países desenvolvidos, têm sido aplicados sobre recipientes de bebidas (garrafas de vidro, vasilhames de plástico e latarias).

Além dos instrumentos econômicos acima relacionados, outros podem ser elencados, tais como empréstimos a juros subsidiados para auxiliar o processo de implantação de equipamentos anti-poluição, a criação e sustentação de mercados para produtos reciclados, o poder de compra do Estado para induzir comportamentos ambientalmente desejáveis entre seus fornecedores etc. Embora seja amplamente reconhecida a importância desses instrumentos, a literatura não tem dado a mesma ênfase que às quatro modalidades comentadas anteriormente, que são consideradas as mais importantes e são de fato as mais aplicadas, principalmente na região da OCDE, onde os instrumentos econômicos são utilizados com mais intensidade.

De uma forma geral, nos países desenvolvidos, os instrumentos de política econômica têm sido cada vez mais adotados como alternativa às políticas de comando e controle, no sentido de aumentar a eficiência da gestão ambiental a custos mais baixos. Parte dessa explicação refere-se às exigências de informação e aos custos administrativos da abordagem de comando e controle, que acabaram por abrir o caminho para as experiências com as abordagens de mercado, conforme apontam Laffont \& Tirole. $^{17}$ Já Schimidheiny ${ }^{18}$ considera as vantagens da abordagem de mercado como fatores determinantes para a sua disseminação. Tais vantagens são: “proporcionar recompensas e incentivos constantes para melhorias contínuas, utilizar os mercados de maneira mais intensiva, incentivar a busca de meios mais eficazes em termos de custo para atingir os objetivos ambientais propostos, e também passar do controle da poluição para a prevenção da poluição".

No entanto, medir a eficiência e eficácia dos instrumentos econômicos exige cautela, pelo fato de estarem inseridos num contexto de política ambiental que também inclui outros aspectos de políticas públicas. Esse contexto é descrito por Barde \& Opschoor, ${ }^{19} \mathrm{e}$ podemos destacar os seguintes fatos:

1. os instrumentos econômicos nunca são aplicados isoladamente. $O$ que os países aplicam, na prática, são combinações de instrumentos econômicos sustentados por
16. GRUBB, Michael. Licenças Negociáveis. In COMISSÃO SOBRE GOVERNANCA GLOBAL. NOSSa Comunidade Global. Rio de Janeiro: Editora da Fundação Getúlio Vargas, 1996 p. 162.

17. LAFFONT, Jean-Jacques; TIROLE, Jean. Environmental Policy, Compliance and Innovation. European Economic Review, v. 38, n. 3,4 , p. 555-562, Apr 1994

18. SCHMIDHEINY, Stephan. Op. cit., p. 21-22.

19. BARDE, Jean-Philippe; OPSCHOOR, Johanes B. Op. cit. 
regulamentações. Com isso, as ênfases dadas em instrumentos individuais variam amplamente de acordo com o tipo de problemática ambiental e o país;

2. a meta principal dos instrumentos econômicos deveria ser a de agir como um incentivo para mudança de comportamento, mas as experiências mostram que nem sempre isso acontece. Em geral, são colocados em níveis mais baixos do que o necessário para induzir essas mudanças. Essa é uma das razões porque os instrumentos e as regulamentações coexistem. Embora embrionária, está emergindo uma tendência para impor sistemas com taxas mais altas, mas a maioria dos países não conta ainda com o suporte político suficiente para implementar uma elevação das taxas e dos impostos;

\section{Em comparação às} abordagens de comando e controle, os instrumentos econômicos estão muito mais próximos dos mecanismos de mercado, deixando aos agentes econômicos maior liberdade para escolherem suas práticas. Por outro lado, com a complexidade e as interrelações de todas as questóes econômicas e ambientais, constituem mais um elemento que, de preferência, deve ser analisado no conjunto, e não como elemento isolado.

3. muitos dos impostos e cobranças mantêm um propósito essencialmente financeiro, ou seja, buscam os recursos monetários para dar suporte a outras medidas de proteção ambiental. Os fundos levantados são destinados a uma série de propósitos: ajudas financeiras de todos os tipos para o setor privado e autoridades locais (bacias aquáticas na França e Holanda); apoiar a reabilitação de áreas poluídas (Super Fund nos Estados Unidos); sustentar projetos de Pesquisa \& Desenvolvimento no controle da poluição, cobrindo os custos administrativos de implementação das políticas de controle da poluição e de medir as emissões, e assim por diante;

4. a reforma tributária já está sendo implementada em alguns países, e está na agenda de outros, a fim de que seja complementar e mutuamente reforçante às políticas ambientais. Como atentam Barde \& Owens, ${ }^{20}$ algumas das taxas e impostos já existentes em alguns países podem ser facilmente identificados como "ambientalmente relevantes e benéficos", como os impostos sobre o uso de transporte e consumo de energia. Outros, porém, têm efeitos perversos, como é o caso da taxação mais baixa sobre o combustível diesel para veículos, os quais induzem a ampliação do sistema de transporte rodoviário, e também sobre os veículos movidos a diesel (os quais podem criar sérios problemas de poluição, em particular a poluição do ar e a poluição sonora nos meios urbanos). Sendo assim, alguns países já começaram a identificar e modificar impostos e taxas distorcidos ambientalmente.

Os países que estão tentando implementar instrumentos econômicos estão encontrando algumas restrições e obstáculos. Alguns desses partem do empresariado, que teme que os instrumentos possam representar apenas um ônus adicional ao processo produtivo, uma vez que já estão sujeitos à regulamentação em vigor. Vale lembrar que os instrumentos econômicos são uma ferramenta de política ambiental, utilizada pelos governos para internalizar os custos ambientais. Mais ainda, não são as únicas ferramentas usadas na implementação de políticas de desenvolvimento sustentável. Em comparação às abordagens de comando e controle, os instrumentos econômicos estão muito mais próximos dos mecanismos de mercado, deixando aos agentes econômicos maior liberdade para escolher suas práticas. Por outro lado, com a complexidade e as interrelações de todas as questões econômicas e ambientais, constituem mais um elemento que, preferencialmente, deve ser analisado no conjunto, e não como elemento isolado.

\section{Auto-regulação}

A auto-regulação é uma outra forma de apoiar a internalização dos custos ambientais, incentivando muito mais as iniciativas do se- 
tor empresarial a adotar práticas ambientais mais sustentáveis que o uso de políticas governamentais mais duras.

As primeiras formas de auto-regulação que surgiram em relação à dimensão ambiental, ocorreram mediante acordos voluntários. Acordo voluntário é um contrato entre autoridades públicas (por exemplo, o Ministério do Meio Ambiente) e a indústria (uma associação comercial ou uma firma individual) ou entre uma firma e uma municipalidade ou associação de moradores locais. Ele acarreta a assinatura de um documento formal pelas partes, sob o qual as associações comerciais, indústrias ou firmas comprometem-se a alcançar uma série de objetivos ambientais. O Governo não está envolvido de nenhuma forma, exceto por um compromisso informal de não adotar regulamentações relativas à atividade coberta pelo acordo voluntário enquanto ele permanecer em vigor. Assim, o contrato tem a força de lei privada, somente, e não acarreta penalidades legais pela quebra de seus termos. ${ }^{21}$

Os acordos voluntários têm sido usados desde a década de 70 , especialmente em países desenvolvidos, algumas vezes para complementar e tornar mais fortes as regulamentações já existentes. Esse é o caso no Japão, onde 40.000 acordos foram concluídos, desde o começo dos anos 70 , por empresas e autoridades locais, e os padrões estabelecidos por eles foram frequientemente mais restritos que os padrões nacionais ou de regulamentações municipais.

De uma forma geral, os acordos voluntários representam benefícios à indústria porque, quando antecipam regulamentações, as empresas ganham mais tempo para realizarem as adaptações necessárias, ou então influenciar a definição de objetivos da política governamental. Além disso, dão ao setor um grau de segurança regulamentar ou estabilidade, devido ao compromisso assumido pelo governo, mesmo informalmente. Sob o ponto de vista empresarial, outras vantagens relacionam-se ao fato de que os acordos voluntários oferecem um incentivo para as firmas investirem em processos de produção mais adequados, em vez de se submeterem aos objetivos ambientais impostos pelas autoridades, além de possibilitarem uma imagem pública mais positiva da indústria.

Há, porém, diversas críticas quanto aos acordos voluntários, normalmente prove- nientes do público e das ONGs. Quanto ao público, não é automaticamente receptivo a esse tipo de iniciativa voluntária porque equivale a pedir ao setor privado que se autopolicie. Já as ONGs são habitualmente bastante desconfiadas de acordos voluntários, porque a maioria deles não dá qualquer penalidade no caso de não obediência, não estando sujeitos a processos legais. Outra crítica diz respeito ao fato de exercerem um papel defensivo, pois normalmente desenvolvem um diálogo apenas com os governos e suas agências regulatórias, e relacionam-se a problemas ambientais específicos e localizados, sem dirigir um programa mais ativo no sentido de a indústria exercer uma responsabilidade ambiental maior.

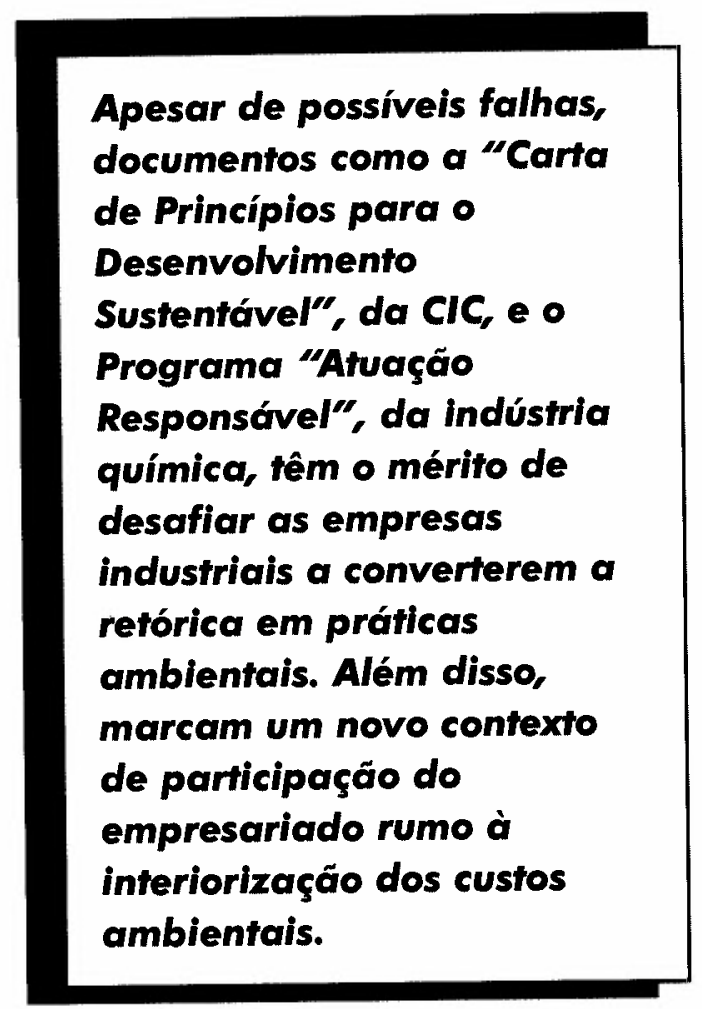

Além dos acordos voluntários, firmados entre uma empresa individual ou associação industrial e autoridades públicas, municipalidade ou comunidade, surgiram outras formas de auto-regulação. Por exemplo: o Programa “Atuação Responsável" (Responsible Care) da indústria química, onde uma indústria em particular compromete-se, unilateralmente, a adotar toda uma série de medidas de proteção ambiental. Essas medidas baseiam-se em seis códigos, a saber: consciência comunitária e resposta de emergência, segurança de processo, prevenção da poluição, distribuição, saúde e se-
21. POTIER, Michel. Agreement on the Environment. The OECD Observer, $\mathrm{n}$. 189, p. 8-11, Aug/Sep 1994 
22. SHRIVASTAVA, Paul. Op. cit., p. 41 , 49.

23. SHRIVASTAVA, Paul. Op. cit., p. 176.

24. ELKINGTON, John. Towards the Sustainable Corporation: Win-Win-Win Business Strategies for Sustainable Development. California Management Review, v. 36, n. 2, p. 90-113, Winter 1994. gurança do trabalhador e ciclo de vida do produto (uma responsabilidade da empresa por seus produtos, da concepção ao pós-uso). $\mathrm{O}$ programa foi instalado em 1985 no Canadá, e, desde então, passou a ser organizado em diversos países pelas associações nacionais do setor, com programas similares.

Uma outra iniciativa, mas desta vez estendendo-se a todos os setores da indústria, foi a "Carta de Princípios para o Desenvolvimento Sustentável", lançada pela Câmara Internacional de Comércio (CIC) em 1991. Até 1994 , mais de 1.100 firmas em todo o mundo já haviam endossado os 16 princípios de conformidade ambiental, compreendidos como metas a serem atingidas.

As principais críticas a esse documento referem-se à sua generalidade e a seu caráter parcialmente reformista. Algumas dessas críticas, mencionadas por Shrivastava,22 abrangem argumentos como "suas idéias, embora excelentes, são muito gerais para criar corporações sustentáveis" e "suas iniciativas são reformistas e não radicais o suficiente, pois permitem que as empresas continuem fazendo o que estão fazendo, com apenas algumas modificações ambientais incrementais".

Apesar de possíveis falhas, documentos como a "Carta de Princípios para o Desenvolvimento Sustentável", da CIC, e o Programa "Atuação Responsável", da indústria química, têm o mérito de colocar às empresas industriais o desafio de converter a retórica em práticas ambientais. Além disso, marcam um novo contexto de participação do empresariado rumo à interiorização dos custos ambientais.

Nesse novo contexto, incluem-se ainda outros códigos de conduta internacionais para a indústria, como os Princípios CERES (Coalition for Environmentally Responsible Economies), de 1990, e o Keidaren Global Environment Charter, de 1991, entre outros

Os Princípios CERES (antigamente chamado Princípios Valdez) datam de 1989, mas uma nova versão foi revista e adotada pelo Conselho de Diretores CERES, em 18 de abril de 1992. Esse Conselho de Diretores representa mais de 500 corporações, incluindo comunidades de ambientalistas e de investimento social que obtêm e prestam informações ao CERES. Os Princípios CERES estabelecem uma ética e padrões ambientais para avaliar atividades de empresas que afetam direta ou indiretamente o meio ambiente e para promover a responsabilidade am- biental, de uma forma que permita acomodar mudanças tecnológicas e realidades ambientais. Os Princípios compreendem:

1. proteção da biosfera;

2. uso sustentável dos recursos naturais;

3. redução e despejo de resíduos;

4. conservação de energia;

5. redução de riscos;

6. comercialização de produtos e serviços seguros;

7. compensação por danos causados ao meio ambiente;

8. informação ao público;

9. compromisso gerencial/administrativo;

10. auditorias e relatórios anuais.

Como forma de criar uma visão ambientalmente sustentável, alguns autores, como Shrivastava, ${ }^{23}$ recomendam às empresas que desejam ser ambientalmente sustentáveis, que adotem a "Carta de Princípios para o Desenvolvimento Sustentável" ou adaptem os Princípios CERES.

De outra forma, pode-se dizer que todos os códigos internacionais de conduta têm tido aceitação entre o empresariado, pelo menos na retórica. A tarefa de disseminação desses códigos tem sido feita especialmente pelas associações de indústrias. Entretanto, têm surgido algumas insatisfações entre os membros dessas associações, levando ao aparecimento de "concorrentes" que estão desenvolvendo uma série de "redes ou consórcios de negócios verdes" e iniciativas relacionadas.

Essas redes de negócios verdes baseiamse particularmente na cooperação e troca de informações entre seus membros, no sentido de incentivar a adoção de práticas ambientais adequadas às suas necessidades, incluindo a contabilização de custos ambientais e o desenvolvimento e implementação de sistemas de gestão ambiental. Dentre essas redes de negócios, podem-se destacar a Iniciativa de Gestão Ambiental Global (Global Environmental Management Initiative GEMI) e o Green World Survey of 50 Countries, nos Estados Unidos, além de uma profusão de organizações tais como o Business in the Environment (BiE), o Advisory Comittee for Business in the Environment (ACBE) e o Prince of Wales' Business Leaders Forum (PWBLF), na Inglaterra, e o BAUM, na Alemanha. ${ }^{24}$ 
A GEMI é uma organização sediada em Washington, Estados Unidos, formada por 20 empresas de grande porte, como a Procter \& Gamble e a AT\&T, entre outras, interessadas em promover a implementação da Carta da CIC. Como diferenciação da Carta original, a GEMI projetou um programa de autoavaliação para ajudar as empresas na quantificação e no acompanhamento de seu progresso quanto aos 16 princípios da carta de intenções. Além disso, conduz conferências e workshops para gerentes e administradores de empresas (com)partilharem as melhores práticas de gestão ambiental. Ademais, incentiva a integração da qualidade ambiental nas práticas das empresas, usando os princípios e ferramentas da Qualidade Total (Total Quality Management - TQM). ${ }^{25}$

No Brasil, também surgiram iniciativas semelhantes de auto-regulação, como o Compromisso Empresarial para a Reciclagem (CEMPRE). Lançado em 1992, trata-se de uma cooperação da iniciativa privada, envolvendo empresas nacionais e multinacionais, a fim de desenvolver e capacitar a indústria nessa área. ${ }^{26}$

De uma forma geral, podem-se verificar esforços ativos por parte da indústria, no sentido de empreender e disseminar práticas ambientais que promovam uma maior responsabilidade das empresas quanto às questões ambientais. Tais iniciativas também têm a preocupação de adequar os princípios de sustentabilidade à realidade dos mercados em que as empresas estão inseridas, verificando suas necessidades e conveniências.

\section{ISO 14000}

Devido à observação das novas exigências de mercado - envolvendo a globalização e a proteção ambiental e a necessidade de inter-relacionálas — está surgindo um sistema de gestão ambiental que pretende ser universal e de caráter voluntário: a ISO 14000.

A ISO (International Standardization Organization) é uma organização não-governamental fundada em 1947, com sede em Genebra, na Suíça, que atua como uma federação mundial de organismos nacionais de normalização. A ISO conta atualmente com mais de 100 membros, sendo um único membro de cada país, entre eles a Associação Brasileira de Normas Técnicas (ABNT). A partir de 1971, a ISO constituiu 3 comitês técnicos, para tratar exclusivamente da normalização de métodos $\mathrm{e}$ análises ambientais: o TC-146 — Qualidade do Ar, o TC-147 — Qualidade da Água, e o TC190 - Qualidade do Solo. Com a elaboração e o lançamento de uma série de normas internacionais de Sistemas de Gestão Ambiental, como a BS 7750 pela British Standards Institution da Grã-Bretanha, em 1992, seguida de outras iniciativas (na França, a AFNOR; na Holanda, a NNI; e na Espanha, a AENOR), a ISO ficou sensibilizada e criou o SAGE (Strategic Advisory Group on Environment), com o objetivo de propor as ações necessárias para um enfoque sistêmico de normalização ambiental e certificação. Os trabalhos do SAGE resultaram na criação do Comitê Técnico (TC) 207 — Gestão Ambiental, em 1993, cujos esforços refletem-se na elaboração do sistema ISO 14000 , que deverá ser implementado ainda em $1996 .^{27}$

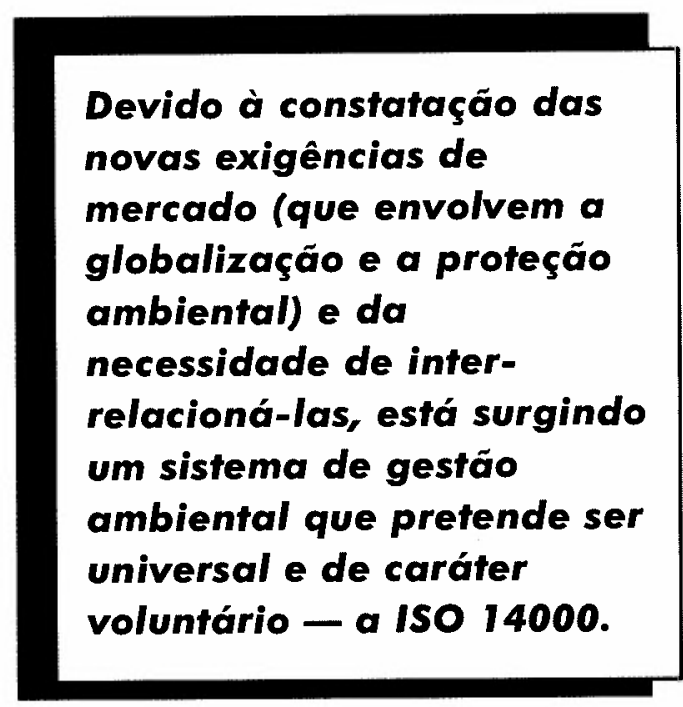

As normas da família ISO 14000 refletem a crescente necessidade da indústria - e também de outras organizações - conhecerem uma legislação ambiental complexa e constantemente em mudança, adequando-se a ela e aos crescentes riscos e responsabilidades, ao controle dos custos ambientais, à necessidade de melhoria contínua e também aos cuidados com a imagem pública das empresas. A ISO 14000 , assim, atende aos ditames de internalização dos custos ambientais de uma forma mais pró-ativa, permitindo ainda que se realizem maiores progressos em relação aos impactos ambientais da indústria.

Assim como todas as iniciativas de autoregulação, a ISO 14000 tem diversas vantagens sobre os mecanismos governamentais de internalização dos custos ambientais, co-
25. ELKINGTON, John. Op. cit.; SHRIVASTAVA, Paul. Op. cit., p. 54.

26. LOUREIRO, Maria R. Gestão Ambiental no Brasil: Aspectos Politicos e Sociais. SãoPaulo: Núcleo de Pesquisas e Publicações/EAESP/FGV (Série Textos Didaticos, n. 13), 1992, p. 25.

27. NAHUZ, Márcio A. R. 0 Sistema ISO 14000 e a certificação ambiental. Revista de Administração de Empresas, v. $35, \mathrm{n}$. 6. p. 55-66, Nov/Dez 1995; REIS, Mauricio J. L. ISO 14000: gerenciamento ambiental: um novo desafio para a sua competitividade. Rio de Janeiro: Qualitymark Ed., 1995, p. 4. 
28. SCHMIDHEINY, Stephan. Op. cit., p. 20-21.

29. AVILA, Joseph A; WHITEHEAD, Bradley W. What is Environmental Strategy?. McKinsey Quarterly, n. 4, p. 53-68, 1993.

30. SCHMIDHEINY, Stephan. Op. cit., p. 20-21.

31. LONG, Bill L. Cleaner Production in OECD Countries. Paris, Industry and Environment, v. 17, n. 4, p. 23-26, OctDec 1994. mentados nas seções anteriores. As principais referem-se ao fato de que evita gastos públicos na coleta de informações, com sua transformação em regulamentos e com o monitoramento de seu efeito, revelando-se assim, como nota Schmidheiny, ${ }^{28}$ mais barata para a sociedade. Para a indústria, em particular, representa uma oportunidade de direcionar e estabelecer os padrões mundiais, empregando as tecnologias disponíveis mais convenientes e evitando a legislação que poderá ser implementada se tais práticas não forem adotadas. Quanto a essas vantagens, Frank P. Popoff, presidente da Dow Chemical, ${ }^{29}$ declara que "se nós falharmos em agir em nosso próprio acordo, iremos nos deparar com mandatos governamentais, $e$ eles serão ineficientes, punitivos e inconsistentes de nação para nação - um atoleiro".

Por outro lado, a abordagem de autoregulação pode ser limitada pelas próprias empresas, pelo menos por aquelas que empregariam "práticas desleais", como o cartelismo ou o não comprometimento. ${ }^{30} \mathrm{De}$ qualquer forma, a adoção da auto-regulação condiz com a busca pelo equilíbrio das forças de mercado e permite a inovação, sendo um grande passo, não só para a internalização dos custos ambientais, mas também para a adoção de práticas mais criativas para lidar com os impactos que a indústria acarreta ao meio ambiente.

\section{EFETIVIDADE DAS MUDANÇAS}

Pelo que foi apresentado até então, podemse verificar amplas discussões no campo da teoria econômica, acerca da questão ambiental e das ferramentas de política econômica, especialmente no que se refere à eficiência e à efetividade. Entretanto, enquanto alguns autores poderiam discutir "qual a melhor ferramenta" para a interiorização dos custos ambientais, parece já estar havendo um consenso quanto à melhor forma de abordar a questão em termos práticos. Esse consenso gira em torno da combinação entre os três mecanismos, e evidencia um melhor entrosamento entre o governo e a indústria no sentido de cooperarem para a proteção ambiental e buscarem a melhor forma de tratar a questão. Como nota Bill L. Long, diretor para Meio Ambiente da OCDE: " $O$ que está emergindo nos países membros da OCDE com respeito às ferramentas de politica ambiental, é uma abordagem híbrida, baseada na procura e aplicação de um mix que inclui regulamentação governamental, instrumentos econômicos de mercado e acordos voluntários ajustados para problemas ambientais especificos".

Assim, o balanço atual das iniciativas ligadas à utilização de mecanismos para incorporação dos custos ambientais na indústria parece ser otimista, particularmente nos países desenvolvidos, a despeito dos obstáculos e barreiras que têm sido encontrados para sua implementação. Isso pode representar uma mudança no comportamento e nos paradigmas da concorrência industrial, no sentido de passar-se a tratar a qualidade do meio ambiente como uma fonte potencial de rentabilidade e vantagem competitiva. Contudo, essa postura ainda não está generalizada pela indústria, embora cada vez mais surjam exemplos de empresas que estão se antecipando às exigências e adotando posturas pró-ativas em relação ao meio ambiente.

\section{CONCLUSÃO}

A ampliação da conscientização de toda a sociedade, no que diz respeito à problemática ambiental, e a busca de um senso comum para lidar com essas questões são transformações em curso, e estão contribuindo para tornar o ambiente de negócios das empresas industriais ainda mais turbulento e imprevisível, uma vez que uma variedade de outras mudanças - na economia internacional e no processo de globalização da produção e do consumo, entre outras - também estão se realizando.

A complexidade e a inter-relação dos problemas existentes acabaram por refletirem-se no âmbito das preocupações dos governos e também das indústrias, resultando no surgimento e desenvolvimento de diversas alternativas voltadas para a motivação de mudanças no comportamento das empresas industriais como, por exemplo, os instrumentos de interiorização dos custos ambientais.

A interiorização dos custos ambientais é uma maneira de equilibrar as forças de mercado e de distribuir mais equiitativamente (em termos monetários) os danos que a sociedade está suportando como efeitos da modificação da qualidade do meio ambiente. As experiências desenvolvidas em todo o mundo quanto aos instrumentos de interiorização dos custos ambientais mostram que as mu- 
danças no sentido de tentar conciliar os diversos interesses envolvidos na questão já estão sendo efetuadas, colocando a todos os agentes (particularmente aos da indústria) o desafio de participar do processo e elevar seus níveis de percepção e atuação. Trata-se, porém, de iniciativas em desenvolvimento e muito ainda deve ser feito no sentido de buscar-se bem-estar e qualidade de vida para toda a população. $\mathrm{O}$ meio ambiente tornouse um elemento-chave para repensarem os valores e ideologias vigentes na sociedade e estabelecerem-se novas formas de pensamento e ação em todas as práticas produtivas.

Quadro 1

\section{Os 16 princípios de conformidade ambiental da CIC}

1. Prioridade corporativa: reconhecer a gestão ambiental entre as mais altas prioridades corporativas, como fator determinante para o desenvolvimento sustentável. Estabelecer políticas, programas e práticas para conduzir operações de uma forma ambientalmente correta.

2. Gestão integrada: integrar totalmente essas políticas, programas e práticas em cada negócio como elemento de gestāo em todas as suas funções.

4. Aperfeiçoamento de processos: promover continuamente as políticas corporativas, programas e desempenho ambiental, levando em consideração o desenvolvimento tecnológico, o conhecimento científico, as necessidades do consumidor e as expectativas da comunidade, partindo dos requisitos da legislação ambiental e correlata, e aplicar os mesmos critérios globalmente.

4. Educação dos funcionários: educar, treinar e motivar os funcionários de forma a conduzir suas atividades de uma maneira ambientalmente responsável.

5. Avaliação prévia: avaliar os impactos ambientais antes de iniciar uma nova atividade ou projeto, antes de desativar ou fechar uma instalação ou abandonar um local.

6. Produtos e serviços: desenvolver e providenciar produtos ou serviços que não apresentem impactos ambientais indevidos, e que sejam seguros para o uso intencionado, eficientes no consumo de energia e recursos naturais. E que possam, ainda, ser reciclados, reutilizados ou dispostos de forma segura no meio ambiente.

7. Orientação aos clientes: orientar e, quando relevante, educar clientes, distribuidores e o público no uso seguro, transporte, estocagem e disposição dos produtos, aplicando considerações similares às provisões de serviços.

8. Instalações $e$ operações: desenvolver, projetar e operar instalações e conduzir atividades levando em consideração o uso eficiente de energia e de materiais, o uso sustentável dos recursos renováveis, a minimização dos impactos ambientais adversos, da geração de resíduos e do uso e disposição segura e correta dos resíduos gerados.

9. Pesquisa: elaborar e promover pesquisa dos impactos ambientais das matérias-primas, produtos, processos, emissões e resíduos associados à produção da empresa e dos meios de minimizar tais impactos adversos.

10. Abordagem preventiva: prevenir impactos ambientais significativos e/ou irreversíveis, modificando a produção, comercialização ou uso de produtos, ou serviços baseados no conhecimento científico e tecnológico.

11. Contratados e fornecedores: promover a adoção desses princípios pelos subcontratados que agem em nome da empresa. Encorajar, e, quando apropriado, exigir melhorias nas suas práticas, tornando-as consistentes e compatíveis com aquelas da empresa e estimular a adoção abrangente desses princípios pelos fornecedores.

12. Prontidão para emergência: desenvolver e manter, onde existem riscos significantes, planos de prevençāo e de emergência em conjunto com serviços emergenciais, autoridades competentes e a comunidade local, reconhecendo o potencial dos impactos fronteiriços.

14. Transferência de tecnologia: contribuir para a transferência de tecnologia e métodos de gestão aos setores industriais e outros públicos interessados.

14. Contribuição ao esforço comum: contribuir para o desenvolvimento das políticas públicas, dos programas governamentais, intergovernamentais e das iniciativas educacionais quanto à conscientização e a proteção ambiental.

15. Abertura às preocupações: promover um diálogo aberto com funcionários e o público, antecipando e respondendo às suas preocupações sobre riscos potenciais e impactos das operações, produtos, resíduos e serviços, incluindo aqueles de significância transfronteiriça e global.

16. Conformidade e comunicação: medir o desempenho ambiental, conduzir auditorias ambientais regulares e avaliaçóes de confomidade com os requisitos da empresa, requisitos legais e com estes princípios; periodicamente providenciar informações apropriadas para o Conselho de Administração, funcionários, autoridades e o público em geral. 